\title{
ROBUSTNESS OF CENTRAL COMPOSITE DESIGN AND MODIFIED CENTRAL COMPOSITE DESIGN TO A MISSING OBSERVATION FOR NON-STANDARD MODELS
}

\author{
Jaja E.I. ${ }^{1}$, Etuk E.H. ${ }^{1}$, Iwundu M.P. ${ }^{2}$ and Amos E. ${ }^{1}$ \\ ${ }^{1}$ Department of Mathematics/Science, Rivers State University, Port Harcourt \\ ${ }^{2}$ Department of Mathematics/Science, University of Port Harcourt.
}

Cite this article:

Jaja E.I., Etuk E.H., Iwundu

M.P., Amos E. (2021),

Robustness of Central

Composite Design and

Modified Central Composite

Design to a Missing

Observation for Non-Standard

Models. African Journal of

Mathematics and Statistics

Studies 4(2), 25-40. DOI:

10.52589/AJMSS-

C5NKOI81.

\section{Manuscript History}

Received: 13 April 2021

Accepted: 30 April 2021

Published: 11 May 2021

Copyright $\odot 2020$ The Author(s). This is an Open Access article distributed under the terms of Creative Commons AttributionNonCommercial-NoDerivatives 4.0 International (CC BY-NC-ND 4.0 ), which permits anyone to share, use, reproduce and redistribute in any medium, provided the original author and source are credited.
ABSTRACT: Missing observations in an experimental design may lead to ambiguity in decision making thereby bringing an experiment to disrepute. Robustness, therefore, enables a process, not to break down in the presence of missing observations. This work constructed a modified central composite design (MCCD) from a four-variable central composite design (CCD) augmented with four center points using the leverage of a hat-matrix. The robustness of the CCD and MCCD were assessed when a design point is missing at the factorial, axial, and center points of the experiment, for a non-standard model, using the loss criterion, $D$ optimality, D-efficiency, and relative D-efficiency. When the designs are complete the MCCD shows higher D-efficiency and $D$-optimality for the non-standard model when compared to the $C C D$. In the absence of an observation from any of the designs, the $C C D$ is found to be a more robust and efficient design compared to the MCCD as it has overall lower loss values at all the factors levels.

KEYWORDS: CCD, MCCD, D-efficiency, D-optimality, Loss Criteria, Missing Observation, Non-Standard Model 


\section{INTRODUCTION}

The expectation of every researcher when conducting an experiment whether natural or simulated is that all the input variables are likely to perform optimally. However, this situation is not always true as most treatment combinations in an experiment may not realize this feat due to a wide variety of field conditions, which may not be anticipated at the inception of the experiment. Non-collection of some relevant data due to unanticipated circumstances such as machine error, or in the event that some of the data points are suspicious and/or are missing may lead to situations when some observations may be missing. Akram (2002) observed that missing observation may affect the eventual estimation of the model parameter, particularly when the design is poorly structured. Missing observations may also disturb the statistical power of the test, thereby offering biased parameter estimation and giving unacceptable decisions; (Iwundu 2017). Analysis of missing observations posed a lot of problems to researchers before now, but some simpler ways of overcoming the problems associated with missing observations may have been developed. These include, but are not limited to replacement of the missing values and/or the application of robust statistical designs against missing observations (Akhtar 2001; Iwundu 2017; Alrweili, et. al. 2019). Some notable findings made in the area of missing observations are found in the works of Hedayat and John (1974) who painstakingly x-rayed robust balanced incomplete block (BIB) design, while Andrews and Herzberg (1979) compensated for the possible loss of observation by maximizing the expected value of the determinant of the information matrix; Ghosh (1982) observed that some design points are more informative than the others in most designs and the effects of missing one or two design points attract a higher loss in efficiency; Herzberg and Andrews (1975) studied the probability of losing an observation at a design point. Furthermore, Ahmed (2014) studied the 'missing values estimation comparison in split-plot design' which shows that one missing value obtains the same estimates, while two or three missing values show that the Coons method is the best. In their work Alrweili, et. al (2019) suggested that Akhtar and Prescot (1986) applied the Minimax loss criterion to evaluate and generate CCDs, which, when applied to a classical CCD with four factors, generated 26 runs. Furthermore, Ahmed et al (2012), considered the multilevel augmented second-order response surface design, robust to missing observations. A response surface can therefore be fitted to predict an experiment where two or more variables are involved. Model fitting is a very vital aspect of experimental design, in that it is done at the inception of the experiment and used to predict or ascertain the optimum response. Montgomery (2013) suggested that the fitted model might be used to generalize or guess the response at various factor levels in an experiment. The resultant study of the outcome is always evaluated with the help of Response Surface Methodology (RSM), which suggests that a system varies with the changing levels of the input variables. The mathematical equation used to fit a response surface methodology is always a polynomial equation. The second-order standard model is normally used to fit a central composite design (CCD) which is made up of a combination of factorial or fractional factorial points, axial and center points. However, not all the terms in the standard model are statistically significant, which may result in the removal of some parameters of a standard model. The equation that is generated as a result of the removal of some parameters in a standard model is called a non-standard model (Myers et. al 2009; Iwundu 2018; Iwundu and Jaja 2017; Alrweili et. al 2019). The second-order nonstandard models shall be applied to the central component designs to generate its associated design matrix, which is used to compute the hat matrix. The leverage of a Hat matrix is used to ascertain the components of the design measure that will be included in the design. The resultant design measure is called the modified central composite design (MCCD). The 
research examines how efficient and robust the CCD and MCCD will perform when one observation is removed using the D-optimality and the relative efficiency and relative loss thereof.

\section{MATERIALS AND METHOD}

Any non-standard second-order response surface model with $k$ design variables and $\mathrm{p}$ parameters may be expressed in matrix form as presented below:

$\underline{Y}=X^{*} \underline{B}+\underline{e}$

The model parameters for the above non-standard model will be $p \leq \frac{(k+1)(k+2)}{2}$

The design measure $\xi_{N}$ for consideration in this work is four variables rotatable CCD augmented with some center points as shown below:

$\xi_{N}=\left[\begin{array}{cccc}x_{11}^{F} & x_{21}^{F} & x_{31}^{F} & x_{41}^{F} \\ x_{12}^{F} & x_{22}^{F} & x_{32}^{F} & x_{42}^{F} \\ \cdot & \cdot & \cdot & \cdot \\ \cdot & \cdot & \cdot & \cdot \\ x_{12^{k}}^{F} & x_{22^{k}}^{F} & x_{32^{k}}^{F} & x_{42^{k}}^{F} \\ x_{11}^{A} & x_{21}^{A} & x_{31}^{A} & x_{41}^{A} \\ x_{12}^{A} & x_{22}^{A} & x_{32}^{A} & x_{42}^{A} \\ \cdot & \cdot & \cdot & \cdot \\ \cdot & \cdot & \cdot & \cdot \\ x_{12 k}^{A} & x_{22 k}^{A} & x_{32 k}^{A} & x_{42 k}^{A} \\ x_{11}^{C} & x_{21}^{C} & x_{31}^{C} & x_{41}^{C} \\ x_{12}^{C} & x_{22}^{C} & x_{32}^{C} & x_{42}^{C} \\ \cdot & \cdot & \cdot & \cdot \\ \cdot & \cdot & \cdot & \cdot \\ x_{1 n_{c}}^{C} & x_{2 n_{c}}^{C} & x_{3 n_{c}}^{C} & x_{4 n_{c}}^{C}\end{array}\right]$

where $x_{i j}^{F}, x_{i j}^{A}, x_{i j}^{C}$ are elements in the design measure corresponding to the factorial, axial, and center points. Furthermore, the factorial is coded as $x_{i j}^{F}= \pm 1$, the axial points will be of the form $x_{i j}^{a}=\left(0, . . \pm \alpha_{i j}, \ldots, 0\right)$ and the center points will be of the form $x_{i j}^{0}=(0, \ldots, 0)$. One or more center points may be added to the design. Worthy of note is that the axial points are used to 
define the design, as the design under consideration shall be rotatable design where $\alpha=(F)^{\frac{1}{4}}$ and $F=2^{k} \mathrm{k}$ is the number of variables in the design measure.

The design matrix $X$ is obtained by using the design measure and the second-order nonstandard model as presented below:

$$
X_{N \times p}=\left(\begin{array}{ccccccccc}
1 & x_{11}^{F} & x_{21}^{F} & x_{31}^{F} & x_{41}^{F} & x_{11}^{F} x_{21}^{F} & x_{21}^{F} x_{31}^{F} & \left(x_{11}^{F}\right)^{2} & \left(x_{41}^{F}\right)^{2} \\
. & . & . & . & . & . & . & . & . \\
. & . & . & . & . & . & . & . & . \\
. & . & . & . & . & . & . & . & . \\
1 & x_{12^{k}}^{F} & x_{22^{k}} & x_{32^{k}}^{F} & x_{42^{k}}^{F} & x_{12^{K}}^{F} x_{22^{K}}^{F} & x_{22^{K}}^{F} x_{32^{K}}^{F} & \left(x_{12^{k}}^{F}\right)^{2} & \left(x_{42^{k}}^{F}\right)^{2} \\
1 & x_{11}^{A} & x_{21}^{A} & x_{31}^{A} & x_{41}^{A} & x_{11}^{A} x_{21}^{A} & x_{21}^{A} x_{31}^{A} & \left(x_{11}^{A}\right)^{2} & \left(x_{41}^{A}\right)^{2} \\
. & . . & . . & . . & . & . & . . & . . & . . \\
. . & . . & . . & . . & . . & . . & . . & . . & . . \\
. . & . . & . . & . . & . . & . . & . . & . . & . . \\
1 & x_{12 k}^{A} & x_{22 k}^{A} & x_{32 k}^{A} & x_{42 k}^{A} & x_{12 k}^{A} x_{22 k}^{A} & x_{22 k}^{A} x_{32 x}^{A} & \left(x_{12 k}^{A}\right)^{2} & \left(x_{42 k}^{A}\right)^{2} \\
1 & x_{11}^{C} & x_{21}^{C} & x_{31}^{C} & x_{41}^{C} & x_{11}^{C} x_{21}^{C} & x_{11}^{C} x_{31}^{C} & \left(x_{11}^{C}\right)^{2} & \left(x_{41}^{C}\right)^{2} \\
. . & . . & . . & . . & . . & . . & . . & . . & . . \\
. . & . . & . . & . . & . . & . . & . . & . . & . . \\
. . & . . & . . & . . & . . & . . & . . & . . & . \\
1 & x_{1 n_{C}}^{C} & x_{2 n_{C}}^{C} & x_{3 n_{C}}^{C} & x_{4 n_{C}}^{C} & x_{1 n_{C}}^{C} x_{2 n_{C}}^{C} & x_{1 n_{C}}^{C} x_{3 n_{C}}^{C} & \left(x_{1 n_{C}}^{C}\right)^{2} & \left(x_{4 n_{c}}^{C}\right)^{2}
\end{array}\right)
$$

The least squares estimate of the vector of unknown parameter $\beta_{\text {is }} \hat{\beta}=\left(X^{T} X\right)^{-1} X^{T} y$,

The estimated response is as presented below:

$$
\hat{y}=X \hat{\beta}=X\left(X^{T} X\right)^{-1} X^{T} y=H y
$$

where $H=X\left(X^{T} * X\right)^{-1} X^{T}$ is called the Hat Matrix and is presented below:

$$
H=X\left(X^{T} X\right)^{-1} X^{T}=[[F][A] \quad[C]]=\left[\begin{array}{cccc}
d_{11} & d_{12} & \ldots & d_{1 N} \\
d_{21} & d_{22} & \ldots & d_{2 N} \\
: & : & \ldots .: & : \\
d_{N 1} & d_{N 2} & \ldots & d_{N N}
\end{array}\right]
$$

The partitioning in the hat matrix shows that some columns within the hat matrix correspond to the factorial points $[F]$, some others correspond to the axial points $[A]_{\text {while others }}$ correspond to the center points $[C]$. The diagonal elements of the hat matrix $d_{i j}$ are the degree of the leverage wielded by the $i^{\text {th }}$ point pulling the model toward its $y$-value. When the values 
of $d_{i i}$ are high, it is expected that the coordinates at that point have a better influence on the regression parameters. However, this unique property of the hat matrix is not always the case in a non-standard model. Therefore, the examination of the hat matrix helps in ascertaining the components of the central composite design that has a lesser influence on the design and is subsequently removed. The remaining observation in the design measure is referred to as the modified central composite design (MCCD).

In the event that $m$ observations are missing from an experiment (the design measure), it, therefore, follows that $m$ row(s) will be missing in the design measure which will, in turn, give rise to a reduction in the design matrix $X$ that will have $m$ row(s) missing and the corresponding model matrix with the missing observations will be presented as $X_{m}$ (where $\mathrm{m}=1,2,3 \ldots$ ) while the remaining shall be presented as $X_{r}$. The relationship between these matrices can be partitioned as follows:

$$
X=\left[\begin{array}{l}
X_{m} \\
X_{r}
\end{array}\right]
$$

Where $X_{m}$ is an $m \times p$ matrix of rows corresponding to the $m$ missing observations, and $X_{r \text { is an }} r \times p_{\text {row matrix of the remaining row that makes up the full design }}$ matrix. The original information matrix shall maintain its dimension irrespective of the missing observation. For any number of the missing observation, the $X^{T} X$ for the complete design is reduced by $X_{m}^{T} X_{m}$. The relationship between the missing design matrix and remaining design matrix will have their information matrices sum up to the original information matrix, the under-listed assertions were culled from (Iwundu 2017; Alweili et. al 2019), the partitioning may be written as

$$
X^{T} X=X_{m}^{T} X_{m}+X_{r}^{T} X_{r}
$$

multiplying both sides of the equation by $X^{T} X$ results in

$$
\begin{aligned}
& I_{p}=\left(X_{m}^{T} X_{m}\right)\left(X^{T} X\right)^{-1}+\left(X_{r}^{T} X_{r}\right)\left(X^{T} X\right)^{-1} \\
& I_{p} \quad \text { is an identity matrix of order } p . \text { By rearranging }
\end{aligned}
$$

$$
\frac{\operatorname{det}\left(X_{r}^{T} X_{r}\right)}{\operatorname{det}\left(X^{T} X\right)}=\operatorname{det}\left[I-\left(X_{M}^{T} X_{M}\right)\left(X^{T} X\right)^{-1}\right]
$$


The component $\left|I-\left(X_{m}^{T} X_{m}\right)\left(X^{T} X\right)\right|$ is called the diagonal element of the $m^{\text {th }}$ compound of $(I-H)$, where $H$ is the hat matrix according to the $m$ missing observations and $I$ is the identity matrix having the same dimension as $H$ (Akhtar 1987).

According to Alweili et. al (2019), the determinant of the complete information matrix using the partitioned matrix above may be expressed

$\left|X^{T} X\right|=\left|X_{m}^{T} X_{m}\right|+\left|X_{r}^{T} X_{r}\right|$

and the resultant relative loss due to any set of missing observations is defined as follows:

$L_{i j}=\frac{\left|X^{T} X\right|-\left|X_{n}^{T} X_{m}\right|}{\left|X^{T} X\right|}$

The relative loss in D-optimality with respect to any missing observation lies within the interval of $0 \leq l \leq 1$

The other steps involved in this study of the robustness of the CCD and MCCD with replicated center points, for a $k$ parameter non-standard model.

Step 1. Set up the design matrices

Step 2. Compute the information matrices and associated normalized matrices.

Step 3. Compute the D-efficiency

Step 4. Compute the loss criterion

\section{RESULTS}

The design measure is a four variables central composite design that is made up of the factorial, axial and the replicated four center points is as shown below: 


$$
\zeta_{28}=\left(\begin{array}{cccc}
-1 & -1 & -1 & -1 \\
1 & -1 & -1 & -1 \\
-1 & 1 & -1 & -1 \\
1 & 1 & -1 & -1 \\
-1 & -1 & 1 & -1 \\
1 & -1 & 1 & -1 \\
-1 & 1 & 1 & -1 \\
1 & 1 & 1 & -1 \\
-1 & -1 & -1 & 1 \\
1 & -1 & -1 & 1 \\
-1 & 1 & -1 & 1 \\
1 & 1 & -1 & 1 \\
-1 & -1 & 1 & 1 \\
1 & -1 & 1 & 1 \\
-1 & 1 & 1 & 1 \\
1 & 1 & 1 & 1 \\
2 & 0 & 0 & 0 \\
-2 & 0 & 0 & 0 \\
0 & 2 & 0 & 0 \\
0 & -2 & 0 & 0 \\
0 & 0 & 2 & 0 \\
0 & 0 & -2 & 0 \\
0 & 0 & 0 & 2 \\
0 & 0 & 0 & -2 \\
0 & 0 & 0 & 0 \\
0 & 0 & 0 & 0 \\
0 & 0 & 0 & 0 \\
0 & 0 & 0 & 0
\end{array}\right)
$$

The four variables nine parameter model is presented below:

$$
y=\beta_{0}+\beta_{1} x_{1}+\beta_{2} x_{2}+\beta_{3} x_{3}+\beta_{4} x_{4}+\beta_{12} x_{1} x_{2}+\beta_{23} x_{2} x_{3}+\beta_{11} x_{1}^{2}+\beta_{44} x_{44}^{2}+\xi
$$

The corresponding design matrix is generated from the design points and the model parameters associated with the non-standard model, which gives a $N \times p=28 \times 9$ design matrix, as shown below: 
African Journal of Mathematics and Statistics Studies

ISSN: 2689-5323

Volume 4, Issue 2, 2021 (pp. 25-40)

$X_{28 \times 9}=\left[\begin{array}{lllllllll}1 & -1 & -1 & -1 & -1 & 1 & 1 & 1 & 1 \\ 1 & 1 & -1 & -1 & -1 & -1 & 1 & 1 & 1 \\ 1 & -1 & 1 & -1 & -1 & -1 & -1 & 1 & 1 \\ 1 & 1 & 1 & -1 & -1 & 1 & -1 & 1 & 1 \\ 1 & -1 & -1 & 1 & -1 & 1 & -1 & 1 & 1 \\ 1 & 1 & -1 & 1 & -1 & -1 & -1 & 1 & 1 \\ 1 & -1 & 1 & 1 & -1 & -1 & 1 & 1 & 1 \\ 1 & 1 & 1 & 1 & -1 & 1 & 1 & 1 & 1 \\ 1 & -1 & -1 & -1 & 1 & 1 & 1 & 1 & 1 \\ 1 & 1 & -1 & -1 & 1 & -1 & 1 & 1 & 1 \\ 1 & -1 & 1 & -1 & 1 & -1 & -1 & 1 & 1 \\ 1 & 1 & 1 & -1 & 1 & 1 & -1 & 1 & 1 \\ 1 & -1 & -1 & 1 & 1 & 1 & -1 & 1 & 1 \\ 1 & 1 & -1 & 1 & 1 & -1 & -1 & 1 & 1 \\ 1 & 1 & 1 & 1 & 1 & -1 & 1 & 1 & 1 \\ 1 & 2 & 0 & 0 & 0 & 0 & 0 & 4 & 0 \\ 1 & 0 & 2 & 0 & 0 & 0 & 0 & 0 & 0 \\ 1 & 0 & -2 & 0 & 0 & 0 & 0 & 0 & 0 \\ 1 & 0 & 0 & 2 & 0 & 0 & 0 & 0 & 0 \\ 1 & 0 & 0 & -2 & 0 & 0 & 0 & 0 & 0 \\ 1 & 0 & 0 & 0 & 2 & 0 & 0 & 0 & 4 \\ 1 & 0 & 0 & 0 & -2 & 0 & 0 & 0 & 4 \\ 1 & 0 & 0 & 0 & 0 & 0 & 0 & 0 & 0 \\ 1 & 0 & 0 & 0 & 0 & 0 & 0 & 0 & 0 \\ 1 & 0 & 0 & 0 & 0 & 0 & 0 & 0 & 0 \\ 1 & 0 & 0 & 0 & 0 & 0 & 0 & 0 & 0\end{array}\right]$

The associated information matrix $X^{T} X$ is presented below:

$$
X^{T} X=\left[\begin{array}{ccccccccc}
28 & 0 & 0 & 0 & 0 & 0 & 0 & 24 & 24 \\
0 & 24 & 0 & 0 & 0 & 0 & 0 & 0 & 0 \\
0 & 0 & 24 & 0 & 0 & 0 & 0 & 0 & 0 \\
0 & 0 & 0 & 24 & 0 & 0 & 0 & 0 & 0 \\
0 & 0 & 0 & 0 & 24 & 0 & 0 & 0 & 0 \\
0 & 0 & 0 & 0 & 0 & 16 & 0 & 0 & 0 \\
0 & 0 & 0 & 0 & 0 & 0 & 16 & 0 & 0 \\
24 & 0 & 0 & 0 & 0 & 0 & 0 & 48 & 16 \\
24 & 0 & 0 & 0 & 0 & 0 & 0 & 16 & 48
\end{array}\right]
$$

Determinant of the information matrix is $1.7395 \times 10^{12}$ 
African Journal of Mathematics and Statistics Studies

ISSN: 2689-5323

Volume 4, Issue 2, 2021 (pp. 25-40)

www.abjournals.org

The normalized information matrix is

$\frac{X^{T} X}{28}=\left[\begin{array}{cccccccccc}1.0000 & 0 & 0 & 0 & 0 & 0 & 0 & 0.8571 & 0.8571 \\ 0 & 0.8571 & 0 & 0 & 0 & 0 & 0 & 0 & 0 \\ 0 & 0 & 0.8571 & 0 & 0 & 0 & 0 & 0 & 0 \\ 0 & 0 & 0 & 0.8571 & 0 & 0 & 0 & 0 & 0 \\ 0 & 0 & 0 & 0 & 0.8571 & 0 & 0 & 0 & 0 \\ 0 & 0 & 0 & 0 & 0 & 0.5714 & 0 & 0 & 0 \\ 0 & 0 & 0 & 0 & 0 & 0 & 0.5714 & 0 & 0 \\ 0.8571 & 0 & 0 & 0 & 0 & 0 & 0 & 1.7143 & 0.5714 \\ 0.8571 & 0 & 0 & 0 & 0 & 0 & 0 & 0.5714 & 1.7143\end{array}\right]$

The determinant of the normalized information matrix is 0.1644

The design efficiency of the complete CCD is $\left|\frac{X^{T} X}{28}\right|^{\frac{1}{9}} \times 100=81.99$

The hat matrix associated with the CCD when the design measure is complete
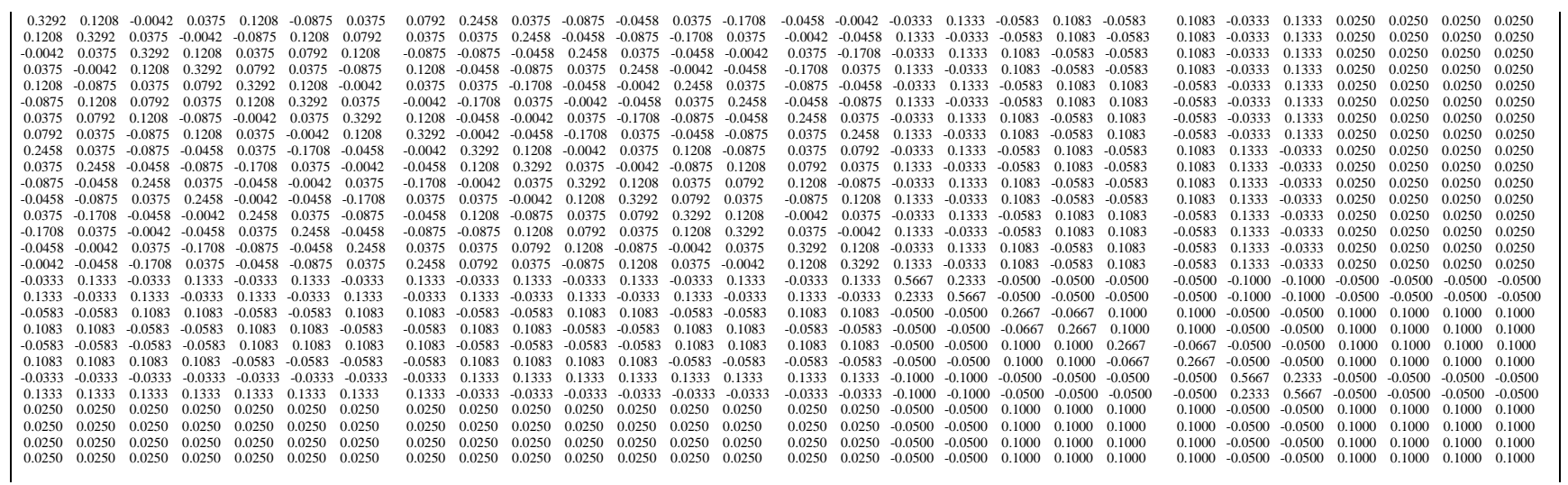

The hat matrix above showed that the diagonal elements at the factorial points are constant at 0.3292 and likewise at the center points at 0.1000 respectively, whereas there are two contrasting diagonal elements at the axial portion of 0.5667 and 0.2667 . From the foregoing, it shows that the design points corresponding to the lower diagonal elements make little or no contributions to the performance of the project and are therefore dropped. The affected design points are $(0,2,0,0),(0,-2,0,0),,(0,0,2,0)$ and $(0,0,-2,0)$. Now, the design measure without these design points is called the Modified Central composite Design. MCCD presented below: 
African Journal of Mathematics and Statistics Studies

ISSN: 2689-5323

Volume 4, Issue 2, 2021 (pp. 25-40)

$\zeta_{M C C D}=\left[\begin{array}{llll}-1 & -1 & -1 & -1 \\ 1 & -1 & -1 & -1 \\ -1 & 1 & -1 & -1 \\ 1 & 1 & -1 & -1 \\ -1 & -1 & 1 & -1 \\ 1 & -1 & 1 & -1 \\ -1 & 1 & 1 & -1 \\ 1 & 1 & 1 & -1 \\ -1 & -1 & -1 & 1 \\ 1 & -1 & -1 & 1 \\ -1 & 1 & -1 & 1 \\ 1 & 1 & -1 & 1 \\ -1 & -1 & 1 & 1 \\ 1 & -1 & 1 & 1 \\ -1 & 1 & 1 & 1 \\ 1 & 1 & 1 & 1 \\ -2 & 0 & 0 & 0 \\ 2 & 0 & 0 & 0 \\ 0 & 0 & 0 & -2 \\ 0 & 0 & 0 & 2 \\ 0 & 0 & 0 & 0 \\ 0 & 0 & 0 & 0 \\ 0 & 0 & 0 & 0 \\ 0 & 0 & 0 & 0\end{array}\right]$

The design points in the MCCD are 24 showing that four design points are non-influential in the CCD and have been dropped. The associated design matrix is

$$
X=\left[\begin{array}{lllllllll}
1 & -1 & -1 & -1 & 0 & 1 & 1 & 1 & 0 \\
1 & -1 & -1 & -1 & 0 & 1 & 1 & 1 & 0 \\
1 & 1 & -1 & -1 & 0 & -1 & 1 & 1 & 0 \\
1 & 1 & -1 & -1 & 0 & -1 & 1 & 1 & 0 \\
1 & -1 & 1 & -1 & 0 & -1 & -1 & 1 & 0 \\
1 & -1 & 1 & -1 & 0 & -1 & -1 & 1 & 0 \\
1 & 1 & 1 & -1 & 0 & 1 & -1 & 1 & 0 \\
1 & 1 & 1 & -1 & 0 & 1 & -1 & 1 & 0 \\
1 & -1 & -1 & 1 & 0 & 1 & -1 & 1 & 0 \\
1 & -1 & -1 & 1 & 0 & 1 & -1 & 1 & 0 \\
1 & 1 & -1 & 1 & 0 & -1 & -1 & 1 & 0 \\
1 & 1 & -1 & 1 & 0 & -1 & -1 & 1 & 0 \\
1 & -1 & 1 & 1 & 0 & -1 & 1 & 1 & 0 \\
1 & -1 & 1 & 1 & 0 & -1 & 1 & 1 & 0 \\
1 & 1 & 1 & 1 & 0 & 1 & 1 & 1 & 0 \\
1 & 1 & 1 & 1 & 0 & 1 & 1 & 1 & 0 \\
1 & 0 & 0 & 0 & 0 & 0 & 0 & 0 & 0 \\
1 & 0 & 0 & 0 & 0 & 0 & 0 & 0 & 0 \\
1 & 0 & 0 & 2 & 0 & 0 & 0 & 0 & 0 \\
1 & 0 & 0 & -2 & 0 & 0 & 0 & 0 & 0 \\
1 & 0 & 0 & 0 & 0 & 0 & 0 & 0 & 0 \\
1 & 0 & 0 & 0 & 0 & 0 & 0 & 0 & 0 \\
1 & 0 & 0 & 0 & 0 & 0 & 0 & 0 & 0 \\
1 & 0 & 0 & 0 & 0 & 0 & 0 & 0 & 0
\end{array}\right]
$$


African Journal of Mathematics and Statistics Studies

ISSN: 2689-5323

Volume 4, Issue 2, 2021 (pp. 25-40)

www.abjournals.org

the information matrix is

$$
X^{T} X=\left[\begin{array}{ccccccccc}
24 & 0 & 0 & 0 & 0 & 0 & 0 & 24 & 24 \\
0 & 24 & 0 & 0 & 0 & 0 & 0 & 0 & 0 \\
0 & 0 & 16 & 0 & 0 & 0 & 0 & 0 & 0 \\
0 & 0 & 0 & 16 & 0 & 0 & 0 & 0 & 0 \\
0 & 0 & 0 & 0 & 24 & 0 & 0 & 0 & 0 \\
0 & 0 & 0 & 0 & 0 & 16 & 0 & 0 & 0 \\
0 & 0 & 0 & 0 & 0 & 0 & 16 & 0 & 0 \\
24 & 0 & 0 & 0 & 0 & 0 & 0 & 48 & 16 \\
24 & 0 & 0 & 0 & 0 & 0 & 0 & 16 & 48
\end{array}\right]
$$

The determinant of the information matrix is $4.6386 \mathrm{e}+011$

The normalized information matrix is

$\frac{X^{T} X}{24}=\left[\begin{array}{rcccccccccc}1.0000 & 0 & 0 & 0 & 0 & 0 & 0 & 1.0000 & 1.0000 \\ 0 & 1.0000 & 0 & 0 & 0 & 0 & 0 & 0 & 0 \\ 0 & 0 & 0.6667 & 0 & 0 & 0 & 0 & 0 & 0 \\ 0 & 0 & 0 & 0.6667 & 0 & 0 & 0 & 0 & 0 \\ 0 & 0 & 0 & 0 & 1.0000 & 0 & 0 & 0 & 0 \\ 0 & 0 & 0 & 0 & 0 & 0.6667 & 0 & 0 & 0 \\ 0 & 0 & 0 & 0 & 0 & 0 & 0.6667 & 0 & 0 \\ 1.0000 & 0 & 0 & 0 & 0 & 0 & 0 & 2.0000 & 0.6667 \\ 1.0000 & 0 & 0 & 0 & 0 & 0 & 0 & 0.6667 & 2.0000\end{array}\right]=$

Determinant of the normalized information matrix is 0.1756

The hat matrix of the MCCD is

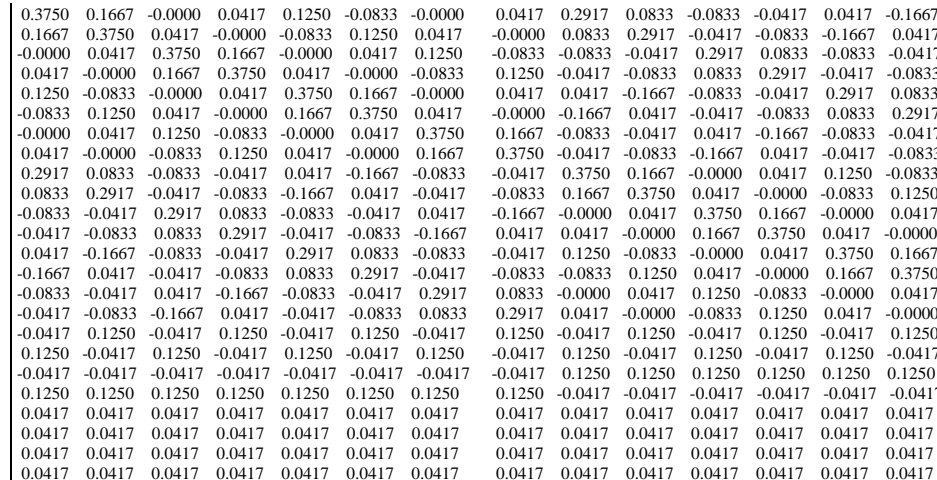

$\begin{array}{llllllllll}-0.0833 & -0.0417 & -0.0417 & 0.1250 & -0.0417 & 0.1250 & 0.0417 & 0.0417 & 0.0417 & 0.0417\end{array}$

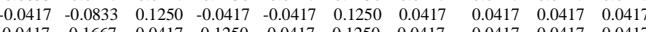

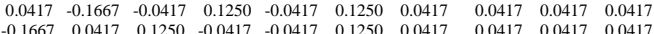
$\begin{array}{llllllllll}-0.1667 & 0.0417 & 0.1250 & -0.0417 & -0.0417 & 0.1250 & 0.0417 & 0.0417 & 0.0417 & 0.0417\end{array}$ $\left.\begin{array}{llllllllll}-0.0833 & -0.0417 & -0.0417 & 0.1250 & -0.0417 & 0.1250 & 0.0417 & 0.0417 & 0.0417 & 0.0417\end{array}\right]$ $\left.\begin{array}{llllllllll}0.0417 & -0.0833 & 0.1250 & -0.0417 & -0.0417 & 0.1250 & 0.0417 & 0.0417 & 0.0417 & 0.0417\end{array}\right]$ $\begin{array}{lllllllllll}0.0833 & 02917 & 0.1250 & -0.12417 & -0.0417 & 0.1250 & 0.0417 & 0.0417 & 0.0417 & 0.0417\end{array}$ $\begin{array}{lllllllllll}-0.0000 & 0.0417 & -0.0417 & 0.1250 & 0.1250 & -0.0417 & 0.0417 & 0.0417 & 0.0417 & 0.0417\end{array}$ $\begin{array}{llllllllll}0.0417 & -0.0000 & 0.1250 & -0.0417 & 0.1250 & -0.0417 & 0.0417 & 0.0417 & 0.0417 & 0.0417\end{array}$ $\begin{array}{llllllllll}0.1250 & -0.0833 & -0.0417 & 0.1250 & 0.1250 & -0.0417 & 0.0417 & 0.0417 & 0.0417 & 0.0417\end{array}$ $\begin{array}{lllllllllll}-0.0833 & 0.1250 & 0.1250 & -0.0417 & 0.1250 & -0.0417 & 0.0417 & 0.0417 & 0.0417 & 0.0417 \\ 0 & 0.0417 & 0.006 & 0.250 & 0.047 & 0.250 & -0.047 & 0.0417 & 0.0417 & 0.047 & 0.0417\end{array}$ $\left.\begin{array}{llllllllll}-0.0000 & 0.0417 & -0.0417 & 0.1250 & 0.1250 & -0.0417 & 0.0417 & 0.0417 & 0.0417 & 0.0417\end{array}\right]$ $\left.\begin{array}{llllllllll}0.0417 & -0.017 & 0.1250 & 0.0447 & 0.1250 & -0.047 & 0.0417 & 0.0417 & 0.047 & 0.0417\end{array}\right]$ $\left.\begin{array}{lllllllllll}0.1667 & 0.3750 & 0.1250 & -0.0417 & 0.1250 & -0.0417 & 0.0417 & 0.0417 & 0.0417 & 0.0417\end{array}\right]$ $\begin{array}{llllllllll}-0.0417 & 0.1250 & 0.5833 & 0.2500 & -0.0833 & -0.0833 & -0.0833 & -0.0833 & -0.0833 & -0.0833\end{array}$ $\begin{array}{llllllllll}0.1250 & -0.0417 & 0.2500 & 0.5833 & -0.0833 & -0.0833 & -0.0833 & -0.0833 & -0.0833 & -0.0833\end{array}$ $\begin{array}{llllllllll}0.1250 & 0.1250 & -0.0833 & -0.0833 & 0.5833 & 0.2500 & -0.0833 & -0.0833 & -0.0833 & -0.0833\end{array}$ $\begin{array}{llllllllll}-0.0417 & -0.0417 & -0.0833 & -0.0833 & 0.2500 & 0.5833 & -0.0833 & -0.0833 & -0.0833 & -0.0833 \\ 0.0417 & 0.017 & -0.083 & -0.0833 & -0.0833 & -0.083 & 0.067 & 0.067 & 0.067 & 0.067\end{array}$ $\left.\begin{array}{lllllllllll}0.0417 & 0.0417 & -0.0833 & -0.0833 & -0.0833 & -0.0833 & 0.1667 & 0.1667 & 0.1667 & 0.1667\end{array}\right)$ $\left.\begin{array}{llllllllll}0.0417 & 0.0417 & -0.0833 & -0.0833 & -0.0833 & -0.0833 & 0.1667 & 0.1667 & 0.1667 & 0.1667 \\ 0.0417 & 0.0417 & 0.0833 & -0.0833 & -0.0833 & 0.0833 & 0.1667 & 0.167 & 0.1667 & 0.667\end{array}\right)$ $\begin{array}{llllllllll}0.0417 & 0.0417 & -0.0833 & -0.0833 & -0.0833 & -0.0833 & 0.1667 & 0.1667 & 0.1667 & 0.1667\end{array}$ 
When the identity treatment $\left[\begin{array}{llll}-1 & -1 & -1 & -1\end{array}\right]$ is missing from the CCD the remaining design measure is

$$
\zeta_{27 \times 4}=\left[\begin{array}{llll}
1 & -1 & -1 & -1 \\
-1 & 1 & -1 & -1 \\
1 & 1 & -1 & -1 \\
-1 & -1 & 1 & -1 \\
1 & -1 & 1 & -1 \\
-1 & 1 & 1 & -1 \\
1 & 1 & 1 & -1 \\
-1 & -1 & -1 & 1 \\
1 & -1 & -1 & 1 \\
-1 & 1 & -1 & 1 \\
1 & 1 & -1 & 1 \\
-1 & -1 & 1 & 1 \\
1 & -1 & 1 & 1 \\
-1 & 1 & 1 & 1 \\
2 & 1 & 1 & 1 \\
-2 & 0 & 0 & 0 \\
0 & 2 & 0 & 0 \\
0 & -2 & 0 & 0 \\
0 & 0 & 2 & 0 \\
0 & 0 & -2 & 0 \\
0 & 0 & 0 & 2 \\
0 & 0 & 0 & -2 \\
0 & 0 & 0 & 0 \\
0 & 0 & 0 & 0 \\
0 & 0 & 0 & 0 \\
0 & 0 & 0 & 0
\end{array}\right]
$$

The design matrix is of the CCD with one missing observation is

$$
X_{m}=\left[\begin{array}{lllllllll}
1 & 1 & -1 & -1 & -1 & -1 & 1 & 1 & 1 \\
1 & -1 & 1 & -1 & -1 & -1 & -1 & 1 & 1 \\
1 & 1 & 1 & -1 & -1 & 1 & -1 & 1 & 1 \\
1 & -1 & -1 & 1 & -1 & 1 & -1 & 1 & 1 \\
1 & 1 & -1 & 1 & -1 & -1 & -1 & 1 & 1 \\
1 & -1 & 1 & 1 & -1 & -1 & 1 & 1 & 1 \\
1 & 1 & 1 & 1 & -1 & 1 & 1 & 1 & 1 \\
1 & -1 & -1 & -1 & 1 & 1 & 1 & 1 & 1 \\
1 & 1 & -1 & -1 & 1 & -1 & 1 & 1 & 1 \\
1 & -1 & 1 & -1 & 1 & -1 & -1 & 1 & 1 \\
1 & 1 & 1 & -1 & 1 & 1 & -1 & 1 & 1 \\
1 & -1 & -1 & 1 & 1 & 1 & -1 & 1 & 1 \\
1 & 1 & -1 & 1 & 1 & -1 & -1 & 1 & 1 \\
1 & -1 & 1 & 1 & 1 & -1 & 1 & 1 & 1 \\
1 & 1 & 1 & 1 & 1 & 1 & 1 & 1 & 1 \\
1 & 2 & 0 & 0 & 0 & 0 & 0 & 4 & 0 \\
1 & -2 & 0 & 0 & 0 & 0 & 0 & 4 & 0 \\
1 & 0 & 2 & 0 & 0 & 0 & 0 & 0 & 0 \\
1 & 0 & 0 & 2 & 0 & 0 & 0 & 0 & 0 \\
1 & 0 & 0 & -2 & 0 & 0 & 0 & 0 & 0 \\
1 & 0 & 0 & 0 & 2 & 0 & 0 & 0 & 4 \\
1 & 0 & 0 & 0 & -2 & 0 & 0 & 0 & 4 \\
1 & 0 & 0 & 0 & 0 & 0 & 0 & 0 & 0 \\
1 & 0 & 0 & 0 & 0 & 0 & 0 & 0 & 0 \\
1 & 0 & 0 & 0 & 0 & 0 & 0 & 0 & 0 \\
1 & 0 & 0 & 0 & 0 & 0 & 0 & 0 & 0
\end{array}\right]
$$


The information matrix $X_{I}^{T} X_{I}$ when the identity row is removed from the CCD is

$\left[\begin{array}{cccccccccc}27 & & 1 & 1 & 1 & 1 & -1 & -1 & 23 & 23 \\ 1 & 23 & -1 & -1 & -1 & 1 & 1 & 1 & 1 \\ 1 & -1 & 23 & -1 & -1 & 1 & 1 & 1 & 1 \\ 1 & -1 & -1 & 23 & -1 & 1 & 1 & 1 & 1 \\ 1 & -1 & -1 & -1 & 23 & 1 & 1 & 1 & 1 \\ -1 & 1 & 1 & 1 & 1 & 15 & -1 & -1 & -1 \\ -1 & 1 & 1 & 1 & 1 & -1 & 15 & -1 & -1 \\ 23 & 1 & 1 & 1 & 1 & -1 & -1 & 47 & 15 \\ 23 & 1 & 1 & 1 & 1 & -1 & -1 & 15 & 47\end{array}\right]$

The D-optimality is $1.1669 \mathrm{e}+12$

The D-efficiency value for the removal of the identity row is 78.27

The loss relative D-optimality when the identity row is missing is $\operatorname{loss}=1-\frac{X_{m}^{T} X_{m}}{X^{T} X}=0.3292$

Table 3.1: Optimality measure and efficiency value for the CCD and MCCD

\begin{tabular}{llll}
\hline Design type & $\operatorname{det}\left(X_{m}^{T} X_{m}\right)$ & $\operatorname{det}\left(\frac{X_{m}^{T} X_{m}}{N}\right)$ & D-Efficiency \\
\hline CCD & $1.7395 \mathrm{e}+12$ & 0.1644 & 81.99 \\
MCCD & $4.6386 \mathrm{e}+11$ & 0.1756 & 82.58 \\
\hline
\end{tabular}

Table 3.2: D-efficiency and loss due to one Missing Observation for the CCD

\begin{tabular}{|c|c|c|c|c|c|}
\hline $\begin{array}{l}\text { Missing design } \\
\text { point }\end{array}$ & $\operatorname{det}\left(X_{m}^{T} X_{m}\right)$ & $\operatorname{det}\left(\frac{X_{m}^{T} X_{m}}{N}\right)$ & D-Efficiency & $\frac{\operatorname{det}\left(X_{m}^{T} X_{m}\right)}{\operatorname{det}\left(X^{T} X\right)}$ & Loss \\
\hline$-1-1-1-1$ & $1.1669 e+12$ & 0.1103 & 78.27 & 0.6708 & 0.3292 \\
\hline $1-1-1-1$ & $1.1669 \mathrm{e}+12$ & 0.1103 & 78.27 & 0.6708 & 0.3292 \\
\hline$-11-1-1$ & $1.1669 \mathrm{e}+12$ & 0.1103 & 78.27 & 0.6708 & 0.3292 \\
\hline $11-1-1$ & $1.1669 \mathrm{e}+12$ & 0.1103 & 78.27 & 0.6708 & 0.3292 \\
\hline$-1-1 \quad 1-1$ & $1.1669 \mathrm{e}+12$ & 0.1103 & 78.27 & 0.6708 & 0.3292 \\
\hline $1-11-1$ & $1.1669 \mathrm{e}+12$ & 0.1103 & 78.27 & 0.6708 & 0.3292 \\
\hline$-1111-1$ & $1.1669 \mathrm{e}+12$ & 0.1103 & 78.27 & 0.6708 & 0.3292 \\
\hline $111-1$ & $1.1669 \mathrm{e}+12$ & 0.1103 & 78.27 & 0.6708 & 0.3292 \\
\hline$-1-1-11$ & $1.1669 \mathrm{e}+12$ & 0.1103 & 78.27 & 0.6708 & 0.3292 \\
\hline $1-1-11$ & $1.1669 \mathrm{e}+12$ & 0.1103 & 78.27 & 0.6708 & 0.3292 \\
\hline$-11-11$ & $1.1669 \mathrm{e}+12$ & 0.1103 & 78.27 & 0.6708 & 0.3292 \\
\hline $11-11$ & $1.1669 \mathrm{e}+12$ & 0.1103 & 78.27 & 0.6708 & 0.3292 \\
\hline$-1-111$ & $1.1669 \mathrm{e}+12$ & 0.1103 & 78.27 & 0.6708 & 0.3292 \\
\hline $1-111$ & $1.1669 \mathrm{e}+12$ & 0.1103 & 78.27 & 0.6708 & 0.3292 \\
\hline-1111 & $1.1669 \mathrm{e}+12$ & 0.1103 & 78.27 & 0.6708 & 0.3292 \\
\hline
\end{tabular}




\begin{tabular}{|c|c|c|c|c|c|}
\hline 1111 & $1.1669 \mathrm{e}+12$ & 0.1103 & 78.27 & 0.6708 & 0.3292 \\
\hline 2000 & $7.5377 \mathrm{e}+11$ & 0.0712 & 74.55 & 0.4333 & 0.5667 \\
\hline-2000 & $7.5377 \mathrm{e}+11$ & 0.0712 & 74.55 & 0.4333 & 0.5667 \\
\hline 0200 & $1.2756 \mathrm{e}+12$ & 0.1206 & 79.05 & 0.7333 & 0.2667 \\
\hline $0-200$ & $1.2756 e+12$ & 0.1206 & 79.05 & 0.7333 & 0.2667 \\
\hline 0020 & $1.2756 \mathrm{e}+12$ & 0.1206 & 79.05 & 0.7333 & 0.2667 \\
\hline $00-20$ & $1.2756 e+12$ & 0.1206 & 79.05 & 0.7333 & 0.2667 \\
\hline 0002 & $7.5377 \mathrm{e}+11$ & 0.0712 & 74.55 & 0.4333 & 0.5667 \\
\hline $\begin{array}{lll}0 & 0 & 0-2\end{array}$ & $7.5377 \mathrm{e}+11$ & 0.0712 & 74.55 & 0.4333 & 0.5667 \\
\hline 0000 & $1.5655 \mathrm{e}+12$ & 0.1480 & 80.87 & 0.9000 & 0.1000 \\
\hline 0000 & $1.5655 \mathrm{e}+12$ & 0.1480 & 80.87 & 0.9000 & 0.1000 \\
\hline $\begin{array}{llll}0 & 0 & 0 & 0\end{array}$ & $1.5655 \mathrm{e}+12$ & 0.1480 & 80.87 & 0.9000 & 0.1000 \\
\hline 0000 & $1.5655 \mathrm{e}+12$ & 0.1480 & 80.87 & 0.9000 & 0.1000 \\
\hline
\end{tabular}

Table 3.3 D-efficiency and loss due to one Missing Observation for the MCCD

\begin{tabular}{|c|c|c|c|c|c|}
\hline $\begin{array}{l}\text { Missing } \\
\text { design point }\end{array}$ & $\operatorname{det}\left(X_{m}^{T} X_{m}\right)$ & $\operatorname{det}\left(\frac{X_{m}^{T} X_{m}}{N}\right)$ & D-efficiency & $\frac{\operatorname{det}\left(X_{m}^{T} X_{m}\right)}{\operatorname{det}\left(X^{T} X\right)}$ & Loss \\
\hline$-1-1-1-1$ & $2.8991 \mathrm{e}+11$ & 0.1097 & 78.32 & 0.6250 & 0.3750 \\
\hline $1-1-1-1$ & $2.8991 \mathrm{e}+11$ & 0.1097 & 78.32 & 0.6250 & 0.3750 \\
\hline $\begin{array}{llll}-1 & 1 & -1 & -1\end{array}$ & $2.8991 \mathrm{e}+11$ & 0.1097 & 78.32 & 0.6250 & 0.3750 \\
\hline $11-1-1$ & $2.8991 \mathrm{e}+11$ & 0.1097 & 78.32 & 0.6250 & 0.3750 \\
\hline$-1-1 \quad 1-1$ & $2.8991 \mathrm{e}+11$ & 0.1097 & 78.32 & 0.6250 & 0.3750 \\
\hline $1-11-1$ & $2.8991 \mathrm{e}+11$ & 0.1097 & 78.32 & 0.6250 & 0.3750 \\
\hline-1111 & $2.8991 \mathrm{e}+11$ & 0.1097 & 78.32 & 0.6250 & 0.3750 \\
\hline $111-1$ & $2.8991 \mathrm{e}+11$ & 0.1097 & 78.32 & 0.6250 & 0.3750 \\
\hline$-1-1-1 \quad 1$ & $2.8991 \mathrm{e}+11$ & 0.1097 & 78.32 & 0.6250 & 0.3750 \\
\hline $1-1-11$ & $2.8991 \mathrm{e}+11$ & 0.1097 & 78.32 & 0.6250 & 0.3750 \\
\hline$-11-11$ & $2.8991 \mathrm{e}+11$ & 0.1097 & 78.32 & 0.6250 & 0.3750 \\
\hline $11-11$ & $2.8991 \mathrm{e}+11$ & 0.1097 & 78.32 & 0.6250 & 0.3750 \\
\hline$-1-111$ & $2.8991 e+11$ & 0.1097 & 78.32 & 0.6250 & 0.3750 \\
\hline $1-111$ & $2.8991 \mathrm{e}+11$ & 0.1097 & 78.32 & 0.6250 & 0.3750 \\
\hline-1111 & $2.8991 \mathrm{e}+11$ & 0.1097 & 78.32 & 0.6250 & 0.3750 \\
\hline 1111 & $2.8991 \mathrm{e}+11$ & 0.1097 & 78.32 & 0.6250 & 0.3750 \\
\hline 2000 & $1.9327 e+11$ & 0.0732 & 74.79 & 0.4167 & 0.5833 \\
\hline-2000 & $1.9327 \mathrm{e}+11$ & 0.0732 & 74.79 & 0.4167 & 0.5833 \\
\hline 0002 & $1.9327 e+11$ & 0.0732 & 74.79 & 0.4167 & 0.5833 \\
\hline 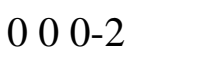 & $1.9327 \mathrm{e}+11$ & 0.0732 & 74.79 & 0.4167 & 0.5833 \\
\hline 00000 & $3.8655 \mathrm{e}+11$ & 0.1463 & 80.77 & 0.8333 & 0.1667 \\
\hline 00000 & $3.8655 e+11$ & 0.1463 & 80.77 & 0.8333 & 0.1667 \\
\hline 00000 & $3.8655 e+11$ & 0.1463 & 80.77 & 0.8333 & 0.1667 \\
\hline 0000 & $3.8655 e+11$ & 0.1463 & 80.77 & 0.8333 & 0.1667 \\
\hline
\end{tabular}




\section{DISCUSSION OF RESULTS}

\section{One missing observations at the factorial, axial, and center points}

The study compared the robustness of the CCD and MCCD with four replicated center points using the D-efficiency and loss principle. The missing observation in the designs occurred at the factorial, axial, and center points as depicted in table 3.2.

From table 3.1 it is evident that the MCCD has higher D-efficiency as well as D-optimality when compared to the CCD, this implies that the MCCD is a better design compared to the $\mathrm{CCD}$ for a non-standard model when no observation is missing.

The reports in table 3.2 and table 3.3 present the results of the relative D-efficiency of the component parts of the Central Composite Design as well as the Modified Central Composite Design in the presence of a missing observation. The tables show that the factorial point of the CCD has a relative D-efficiency value of $78.27 \%$ as against $78.32 \%$ for the MCCD. The axial point likewise has a relative D-efficiency value of $74.55 \%$ and $79.05 \%$ respectively. The design points with higher relative efficiency values correspond to the points that are not influential to the design and were subsequently removed, while the MCCD presents a relative efficiency of $74.79 \%$. At the center point, the CCD has a relative efficiency value of $80.87 \%$ as against $80.77 \%$ relative D-efficiency for the MCCD. From the foregoing, the MCCD is relatively more efficient at the Factorial and Axial points, while the CCD is relatively more efficient at the center point.

When table 3.2 and table 3.3 are considered concerning the losses incurred. The tables reveal that the maximum losses associated with the CCD in the presence of a missing observation are 0.3292 at the factorial points, 0.5667 and 0.2667 at the axial points, and 0.1000 at the center points, while the MCCD shows 0.3750 at the factorial points, 0.5833 at the axial points and 0.1667 at the center points. The minimum-maximum loss (minimaxloss) of the CCD is 0.1000 and that of the MCCD is 0.1667. From the foregoing, the design that minimizes the maximum loss is the CCD. This shows that the CCD is more robust than the MCCD

\section{SUMMARY}

Robustness is the process that yields a good performance of an experiment when some observations are missing. Missing observations through challenges could be mitigated through robust experimentation. This work constructed a modified central composite design from a central composite design for a non-standard model using the leverage principles of the hatmatrix. The study investigated the robustness of central composite design and modified central composite design augmented with four center points in the presence of a single missing observation at the factorial points, axial distances, and center points. The relative efficiency and losses were computed and analyzed for the CCD and MCCD to ascertain the design that is more robust to missing data points. A comparative study of the designs was carried out and the results show that the $\mathrm{CCD}$ exhibits the minimaxloss principle and therefore significantly more robust than the MCCD. Further examination of the result shows that the MCCD is relatively more efficient at the factorial and axial points, while the CCD is more efficient at the center point. 


\section{REFERENCES}

Ahmad T, Akhtar M, and Gilmour SG. (2012) Multilevel augmented pairs second-order response surface designs and their robustness to missing data. Comput Stat Theory and Methods.;41(3):437-452.

Ahmed, L. A. (2016) Missing values estimation comparison in split-plot design, International Journal of computer and information technology. volume 05.

Akhtar, M. and Prescott, P. (1986) Response Surface Designs Robust to missing Observations, Communications in Statistics-Simulation, 15 (2) (1986) 245-363.

Akram, M. (2002). Central composite designs robust to three missing observations, doctorate. The Islamia University Bahawalpur, Pakistan.

Alrweili, H., Georgiou, S. and Stylianou, S.(2019). Robustness of response surface designs to missing data, qual reliab engng int 13:351288-1296

Andrew, D. F. and Herzberg A. M.(1979) The robustness and optimality of response surface designs. J Stat SocB. 38:284-289

Chandrika, L. P., and Fereidoon, S. (2005) Optimization of extraction of phenolic compounds from wheat using response surface methodology, Food Chem. Pp.47-56, 2005.

Dekker, R. and Nicolai, R, (2009). Automated response surface methodology for simulation optimization models with unknown variance, quality technology, and quantitative management vol. 6, no. 3, pp325-352

Ghosh S. (1982) Robustness of BIB designs against non-availability of data, J stat Plan Infer. 6:29-32

Hedayat, A, and John, P.W.M., ( 1974), Resistant and Susceptible Designs, Annals of

Herzberg A M, Andrews D.F(1976) Some considerations in the optimal design of experiments in non-optimal situations. J R Stat Soc B;38:284-289.

Herzberg, A. and Andrew, D. (1975) The robust design of experiments. Bull int stat inst 45:(II):370-374

Iwundu, M. P. (2017) Missing observations: the loss in relative A-, D-, and G-efficiency. International journal of advanced mathematical sciences,5(2) 43-49

Iwundu, M. P. (2018) Construction of Modified Central Composite Designs for Non-standard Models, International Journal of Statistics and Probability; 7(5)

Iwundu, M. P., and Jaja, E. I. (2017). Precision of full polynomial response surface designs on models with missing coefficients, international journal of advanced statistics and probability,5 (1) (2017)32-36

Iwundu, M.P. (2018) On the compounds of hat matrix for six-factor central composite design with fractional replicates of the factorial portion. American Journal of Computational And Applied Mathematics.7(4),95-114.

Montgomery (2013).Design and analysis of experiments, $8^{\text {th }}$ edition, New York. John Wiley \& Sons, Inc.

Muthuvelayudham, R. and Viruthagiri, T. (2010). Application of central composite design based response surface methodology in parameter optimization and on cellulose production using agricultural waste, international journal of chemical and biological engineering 3(2),97-104

Myers, R.H., Montgomery, D. C. and Anderson-Cook, C.M. (2009). Response Surface Methodology: Product and Process Optimization Using Designed Experiments, 3rd Edition, John Wiley \& Sons, New York.Statistics, 2, 148-158.

Wang, L. (2006). Recommendation for designs parameters for central composite design with restricted randomization 